\title{
Antalya ilinde yetiştirilen kışlık ekmeklik buğdayın bor beslenme durumunun belirlenmesi
}

\section{Determination of boron nutrition status of winter bread wheat grown in Antalya province}

\author{
Selahattin Bora YALIN ${ }^{1}$, Şule ORMAN ${ }^{2}$, Hüseyin OK ${ }^{2}$, Aylin ZAMBAK ÖZGÜR ${ }^{\circledR}$ \\ ${ }^{1}$ Korkuteli İlçe Gıda Tarım ve Hayvancılık Müdürlüğü, Korkuteli /Antalya \\ ${ }^{2}$ Akdeniz Üniversitesi, Ziraat Fakültesi, Toprak Bilimi ve Bitki Besleme Bölümü, 07070, Antalya \\ Sorumlu yazar (Corresponding author): Ş. Orman, e-posta (e-mail): suleorman@akdeniz.edu.tr \\ Yazar(lar) e-posta (Authore-mail): sbora.yalin@gmail.com, huseyinok@akdeniz.edu.tr, aylin_z@hotmail.com
}

\section{MAKALE BİLGİSİ}

Alınış tarihi 12 Mart 2019

Düzeltilme tarihi 19 Nisan 2019

Kabul tarihi 26 Nisan 2019

\section{Anahtar Kelimeler:}

Bor

Bitki besleme

Ekmeklik buğday

İnsan beslenmesi

Tarımsal biyofortifikasyon

\begin{abstract}
ÖZ
Dünya üzerinde en çok üretilen ve tüketilen tahıl olan buğday, canlı beslenmesi açısından çok önemli bir stratejik üründür. Bu çalışmada Antalya ilinde yetiștirilen kışlık ekmeklik buğday bitkisinin bor beslenme durumu incelenmiş̧tir. Bu amaçla bölgede buğday tarımının en yoğun yapıldığı Aksu, Döşemealtı ve Korkuteli ilçelerinde örnekleme yapılmıştır. Her bir ilçede bölgeyi temsil edecek on farklı buğday tarlasından toprak, bitki, dane örnekleri alınmış ve bor konsantrasyonları belirlenmiştir. Bor konsantrasyonları topraklarda $0.010-1.115 \mathrm{mg} \mathrm{kg}^{-1}$; yapraklarda $0.039-17.51 \mathrm{mg} \mathrm{kg}^{-1}$; danelerde ise $0.010-6.82 \mathrm{mg} \mathrm{kg}^{-1}$ değerleri arasında değişmektedir. Alınabilir bor içeriği yeterlilik sınırı 0.5-2.0 $\mathrm{mg} \mathrm{kg}^{-1} \mathrm{kabul}$ edilerek değerlendirildiğinde toprakların $\% 90$ 'nının bu değerin altında yer aldığı tespit edilmiștir. Buğday bayrak yapraklarının bor konsantrasyonlarının \%80'i yeterli $\left(3-25 \mathrm{mg} \mathrm{kg}^{-1}\right)$ ve $\% 20$ 'sinin yetersiz $\left(3 \mathrm{mg} \mathrm{kg}^{-1}>\right.$ ) sınıfinda yer aldığı belirlenmiştir. Üreticilerle yapılan görüşmede yapraktan bor uygulaması yapıldığı belirtilmiştir. Dane örneklerinin ise \%60'ında yetersiz (2 $\mathrm{mg} \mathrm{kg}^{-1}>$ ) ve \% 40 'nnda yeterli (2-8 $\left.\mathrm{mg} \mathrm{kg}^{-1}\right)$ bor konsantrasyonları tespit edilmiștir. Buğday'da dane verimi kadar danenin mineral içeriği de önemlidir. Bor insan beslenmesi açısından gerekli bir mikrobesin elementidir. Dünya Sağlık Örgütü yetişkin sağlıklı bir insanın beslenme yoluyla günde 1$13 \mathrm{mg}$ bor alabileceğini bildirmektedir. İnsanların beslenmelerinde bor alım kaynakları bitkilerdir. Buğday'dan elde edilen gıda ürünlerinin insanların günlük beslenmesinde ne denli önemli olduğu dikkate alındığında ve gizli açlık olarak adlandırılan mineral element eksikliklerinin sağlık üzerine olumsuz etkileri anlaşıldıkça bu sorunun çözülmesi gerektiğgi düşünülmektedir. Bu nedenle bor uygulama dozu, zamanı ve tekrar sayısı gibi değişkenlerin optimize edilmesi için bilimsel çalışmaların sürdürülmesinde yarar vardır.
\end{abstract}

\section{ARTICLE INFO}

Received 12 March 2019

Received in revised form 19 April 2019

Accepted 26 April 2019

\section{Keywords:}

Boron

Plant nutrition

Bread wheat

Human nutrition

Agronomic biofortification

\begin{abstract}
Wheat, which is the most produced and consumed grain on the world, is a very important strategic product in terms of live nutrition. Boron nutrition status of winter bread wheat plant grown in Antalya province was investigated in this study. For this purpose, sampling was made in Aksu, Döşemealtı and Korkuteli districts where the most of wheat cultivation was made in the region. Soil, plant, grain samples were taken from ten different wheat fields and boron concentrations were determined in each district. Boron concentrations in soils are $0.010-1.115 \mathrm{mg} \mathrm{kg}^{-1} ; 0.039-17.51$ $\mathrm{mg} \mathrm{kg}^{-1}$ on leaves; and between $0.010-6.82 \mathrm{mg} \mathrm{kg}^{-1}$. It was determined that $90 \%$ of the soils were found to be below this value when evaluated by considering $0.5-2 \mathrm{mg} \mathrm{kg}^{-1}$ as the limit of available boron content. It was determined that $80 \%$ of the boron concentrations of wheat flag leaves were sufficient (3-25 mg kg-1) and 20\% were insufficient $\left(3 \mathrm{mg} \mathrm{kg}^{-1}>\right)$. In the interview with the producers, it was stated that foliar boron application was made. In $60 \%$ of the grain samples, inadequate $\left(2 \mathrm{mg} \mathrm{kg}^{-1}>\right)$ and sufficient in $40 \%\left(2-8 \mathrm{mg} \mathrm{kg}^{-1}\right)$ boron concentrations were determined. Boron is a micronutrient element necessary for human nutrition. The World Health Organization reports that an adult healthy person can take $1-13 \mathrm{mg}$ of boron per day via nutrition. Therefore, it is useful to continue scientific studies to optimize variables such as boron application dose, time and number of repetitions.
\end{abstract}




\section{Giriş}

Mutlak gerekli bir bitki besin elementi olan borun bitkide eksikliği ile toksite sınırı birbirine çok yakındır (Brown ve ark. 2002). Bu sebeple ülkemizde noksanlığına da toksitesine de rastlanmaktadır (Kızılgöz ve Özberk 2005). Ayrıca kültür bitkilerinde noksanlığına dünya genelinde en çok rastlanan mikro elementlerden biri de bor'dur (Gupta 1993). Orta Anadolu'da 830 toprak örneğinde yapılan bir çalışmada incelenen toprakların \%62.3'ünün bitkilerce alınabilir B miktarının eşik değer olan $0.5 \mathrm{mg} \mathrm{kg}^{-1}$ 'dan daha az, \%2.5'inin ise toksik sınır değeri olan $2.5 \mathrm{mg} \mathrm{kg}^{-1}$ 'dan daha fazla bor içerdiği bildirilmiştir (Eyüpoğlu ve ark. 2002). Borun bitkiler için yarayışlılığını etkileyen organik madde içeriği, $\mathrm{pH}, \mathrm{Ca}$ ve $\mathrm{K}$ içeriği, kil tipi ve miktarı ile nem kapsamı gibi toprak özellikleri de bitkilerin bor beslenmesini etkileyen diğer faktörlerdir. Transpirasyonun etkisi ile bitkide yukarı doğru taşınan bor hareketsiz bir elementtir (Michael 1969). Bitkilerin bor beslenmesinde ve translokasyonunda bitkinin su tüketimi ve ksilem aktivitesinin etkili olduğu belirlenmiştir (Pate 1975; Shelp ve ark. 1992). Ayrica bu iletimin bitki türleri arasında büyük farklllıklar gösterdiği bilinmektedir (Marschner 1976). Bitkilerin bor gereksinimleri oldukça azdır ve tek çenekli bitkiler çift çeneklilere göre daha az bora ihtiyaç duyar (Marschner 1995). Bergmann (1992)'a göre bitkilerde kritik bor noksanlık seviyelerini buğdaygillerde (örneğin arpa, buğday vb.) $5-10 \mathrm{mg} \mathrm{kg}^{-1}$, çift çenklilerde (örneğin üçgül vb.) 20-70 mg $\mathrm{kg}^{-1}$ ve haşhaşta $80-100 \mathrm{mg} \mathrm{kg}^{-1}$ olarak bildirmiştir. Tahılların bora karşı duyarlı bitkiler olduğu bilinmektedir (Eaton 1944). Ancak yapılan araştırmalarda bor eksikliğinin çevre, toprak ve bitki faktörlerine bağlı olarak ortaya çıkabildiği gözlenmiştir (Shorrocks 1997). Bor, bitkilerin hücre duvarının dayanıklılığında, membran bütünlüğünde, fenol metabolizmasında, karbonhidratların taşınmasında ve generatif organların oluşumunda, polen çimlenmesinde ve polen tüpü büyümesinde önemli roller üstlenmektedir (Marschner 1995). Borun bitkide rol aldığı bu kritik görevler nedeniyle bor stresinin bitkide verim ve kalite üzerine önemli etkiler yaptığ 1 bilinmektedir. Bazı kaynaklarda yetiştirme ortamında bulunan borun $1 \mathrm{mg} \mathrm{kg}^{-1}$ den fazla olmasi yeterli olarak kabul edilirken bazı kaynaklarda $<0.5 \mathrm{mg} \mathrm{kg}^{-1}$ az, $0.5-2.0 \mathrm{mg} \mathrm{kg}^{-1}$ yeterli, 2.1 $5.0 \mathrm{mg} \mathrm{kg}{ }^{-1}$ fazla, $>5.0 \mathrm{mg} \mathrm{kg}{ }^{-1}$ ise çok fazla olarak kabul edilmektedir (Miller 1998; Eyüpoğlu ve ark. 2000). Buğday, yetiştirme ortamında bulunan $2 \mathrm{mg} \mathrm{kg}^{-1}$ boru tolere etmekte ve bu seviyenin üzerindeki bordan ise olumsuz yönde etkilenmektedir (Gupta ve ark. 1985). Buğdayın beslenmesinde bor noksanlığının etkisi, genellikle sterilitenin oluşması ve tane tutumunun azalmasıly verimin sınırlandırılması şeklinde ortaya çıkmaktadır. Bor noksanlığı olan alanlarda özellikle duyarlı çeşitlerde bor gübrelemesiyle sterilitenin azaldığ 1 (Rerkasem ve Jamjod 1989; Subedi ve ark. 1997; Laila ve Adel 2002), tane tutumu (Cheng ve Rerkasem 1993) ve başaktaki tane sayısı ile birlikte tane veriminin arttı̆ $\breve{1}_{1}$ (Pant ve ark. 1998) araştırıcılar tarafindan rapor edilmiştir. Hızla artan dünya nüfusu ve son y1llarda etkisi daha fazla hissedilen küresel isınmanın bir sonucu olarak buğday, insan beslenmesi ve yaşamın devamlılığ açısından stratejik bir bitki olma özelliğini güçlendirerek sürdürmektedir. Türkiye 2017 yılında kişi başı $182 \mathrm{~kg}$ buğday tüketimi ile dünyada en fazla buğday tüketen ülkelerden biridir (TÜIK 2018). Ülkemizde buğday üretiminin artan nüfusumuzu besleyebilmesi için birim alandan elde edilen ürün miktarının ve kalitesinin iyileştirilmesi önemlidir. Ayrıca buğdayın besin içeriğinde sağlanabilinecek zenginleşme ile bu ürünleri tüketen insanların sağlığına da olumlu etki sağlamak olasıdır. Bu noktada daha önce yapılan çalışmalar göstermektedir ki özellikle ekmeklik buğday üretiminde bor beslenmesi çok kritik role sahiptir (Taban ve Erdal 2000; Güneş ve ark. 2003). Toprakları yüksek $\mathrm{pH}$ ve kireç içeriğine sahip bölgemizde bor beslenmesi, üzerinde önemle durulması gereken bir konudur. $\mathrm{Bu}$ çalışmada Antalya ilinde kışlık ekmeklik buğday yetiştirilen alanların bor içerikleri ile birlikte bu alanlarda yetiştirilen buğdayın bor beslenme durumunun belirlenmesi hedeflenmiştir.

\section{Materyal ve Yöntem}

\subsection{Materyal}

Kışlık yetiştirme sezonunda, Antalya ili Aksu, Döşemealtı ve Korkuteli ilçelerinde bulunan her bir ilçeden 10'ar adet olmak üzere 30 adet ekmeklik buğday tarlasından toprak, yaprak ve dane örnekleri alınmıştır.

\subsection{Toprak örneklerinin alınması ve analiz yöntemleri}

Örnekleme noktalarından Jackson (1967) tarafindan bildirilen usullere uygun olarak $0-30 \mathrm{~cm}$ derinlikten alınan toprak örnekleri kurutularak $2 \mathrm{~mm}$ elekten elenmiş ve analize hazırlanmıştır. Toprak örneklerinde; hidrometre yöntemiyle bünye Bouyoucos (1952)'ye göre, Scheibler kalsimetresi ile volümetrik olarak kireç Nelson ve Sommers (1982)'ye göre, modifiye Walkley-Black yaş yakma yöntemiyle organik madde Jackson (1967)'ye göre, 1:2.5'lik toprak-su karışımında pH ve elektriksel iletkenlik (EC) U.S. Soil Survey Staff (1951)'e göre, alınabilir bor analizi Cartwright ve ark. (1983)'e göre yapılmıştır. Elde edilen değerler sınıflandırılırken toprak pH'1 Kellog (1952)'e göre, elektriksel iletkenlik U.S. Soil Survey Staff (1951)'e göre, kireç düzeyleri Evliya (1964)'e göre, bünye sınıflandırması Black (1957)'e göre ve organik madde kapsamları Black (1965)'e göre belirlenmiştir.

\subsection{Yaprak örneklerinin alınması ve analiz yöntemleri}

Örnekleme dönemlerinde bayrak yaprak ve dane örnekleri alanı temsil edecek şekilde alınarak uygun koşullarda saklanmış ve kısa sürede laboratuvara getirilmiştir. Örnekler saf su ile yıkanıp $65^{\circ} \mathrm{C}$ kurutma dolabı kullanılarak son iki tartım sabit kalıncaya kadar kurutulmuş ve bitki öğütme değirmeninde öğütülerek analize hazır hale getirilmiştir (Kacar 1972). Bitki örneklerinden yaş yakma Kacar ve İnal (2008)'e göre gerçekleştirilmiştir. Elde edilen süzükte bor konsantrasyonları ICP-OES (Inductively Coupled Plasma) kullanılarak belirlenmiştir.

\section{Bulgular ve Tartışma}

Analiz edilen toprakların genel bir değerlendirmesini yaptığımızda \%77'si hafif alkali, \%80'i yüksek ya da üzeri kireçli, tamamı tuzsuz, genel olarak kil içeriği yüksek ve \%93'ünün \%2'nin üstünde organik madde içerdiği tespit edilmiştir. Sonuçlar değerlendirildiğinde özellikle toprağın yüksek $\mathrm{pH}$ ve kireç içeriği nedeniyle bor beslenmesinin olumsuz etkilenebileceği düşünülmektedir (Çizelge 1). Bennett ve Mathias (1973)'e göre; genelde ortam pH's1 6.3-6.5 olduğu zaman en yüksek düzeye ulaşan B alımı pH'ın artması ile hızla azalır. Benzer şekilde Bartleta ve Picarelli (1973)'a göre toprak pH'sındaki artışa ve gereğinden fazla kireçlemeye bağlı olarak bitkilerde $\mathrm{B}$ alımının azaldığını bildirmişlerdir. Ayrıca topraktaki değişebilir iyonlar, toprak pH'sı, toprağın ıslanması ve kurumas1, toprak/su oranı gibi faktörlerin de bitkilerin B alımını etkilediğini göstermiştir (Keren ve Bingham 1985; Goldberg 1997). 
Çizelge 1. Toprakların bazı fiziksel ve kimyasal özellikleri.

Table 1. Some physical and chemical properties of soils.

\begin{tabular}{|c|c|c|c|c|c|c|c|c|c|c|}
\hline \multirow{2}{*}{ Toprak Özelliği } & \multirow{2}{*}{ Sınır Değeri } & \multirow{2}{*}{ Değerlendirme } & \multicolumn{2}{|c|}{ Aksu } & \multicolumn{2}{|c|}{ Döşemealtı } & \multicolumn{2}{|c|}{ Korkuteli } & \multicolumn{2}{|c|}{ Toplam } \\
\hline & & & Örn. Say. & $\%$ & Örn. Say. & $\%$ & Örn. Say. & $\%$ & Örn. Say. & $\%$ \\
\hline \multirow{5}{*}{$\mathrm{pH}$} & $6.1-6.5$ & Hafif Asit & - & - & 1 & 10 & - & - & 1 & 3.33 \\
\hline & $6.6-7.3$ & Nötr & - & - & 4 & 40 & 1 & 10 & 5 & 16.66 \\
\hline & $7.4-7.8$ & Hafif Alkali & 9 & 90 & 5 & 50 & 9 & 90 & 23 & 76.67 \\
\hline & 7.9-8.4 & Alkali & 1 & 10 & - & - & - & - & 1 & 3.33 \\
\hline & $2.6-5.0$ & Kireçli & - & - & 4 & 40 & 2 & 20 & 6 & 20.00 \\
\hline \multirow{3}{*}{$\mathrm{CaCO}_{3}(\%)$} & $5.1-10.0$ & Yüksek & - & - & 3 & 30 & 3 & 30 & 6 & 20.00 \\
\hline & $10.1-20.0$ & Çok Kireçli & - & - & 3 & 30 & - & - & 3 & 9.00 \\
\hline & $20.0<$ & Aşırı Kireçli & 10 & 100 & 1 & 10 & 5 & 50 & 16 & 51.00 \\
\hline \multirow[t]{2}{*}{$\mathrm{EC}\left(\mathrm{dS} \mathrm{m} \mathrm{m}^{-1}\right)$} & $2.5>$ & Tuzsuz & 10 & 100 & 10 & 100 & 10 & 100 & 10 & 100 \\
\hline & & Kumlu Tin & - & - & - & - & 1 & 10 & 1 & 3.33 \\
\hline \multirow{7}{*}{ Bünye } & & Tin & 3 & 30 & 1 & 10 & 2 & 20 & 6 & 20.00 \\
\hline & & Kumlu Killi Tin & - & - & 2 & 20 & - & - & 2 & 6.66 \\
\hline & & Killi Tin & 1 & 10 & 2 & 20 & 2 & 20 & 5 & 16.65 \\
\hline & & Siltli Tin & 1 & 10 & - & - & - & - & 1 & 3.33 \\
\hline & & Siltli Killi Tın & 2 & 20 & - & - & - & - & 2 & 6.66 \\
\hline & & Siltli Kil & 2 & 20 & - & - & - & - & 2 & 6.66 \\
\hline & & Kil & 1 & 10 & 5 & 50 & 5 & 50 & 11 & 36.33 \\
\hline \multirow{2}{*}{ Organik Madde (\%) } & $0-2$ & Humusca Fakir & - & - & - & - & 2 & 20 & 2 & 6.66 \\
\hline & $2-5$ & Az Humuslu & 10 & 100 & 10 & 100 & 8 & 80 & 28 & 93.24 \\
\hline
\end{tabular}

Toprakların bor konsantrasyonları incelendiğinde tüm örnekler genelinde dağılım 0.01-1.15 mg kg-1 aralığında değişmiş ve ortalama bor konsantrasyonu $0.155 \mathrm{mg} \mathrm{kg}^{-1}$ olarak tespit edilmiştir (Çizelge 2). Toprakların B durumlarının değerlendirilmesinde $<0.5 \mathrm{mg} \mathrm{kg}^{-1}$ az, $0.5-2.0 \mathrm{mg} \mathrm{kg}^{-1}$ yeterli, 2.1-5.0 $\mathrm{mg} \mathrm{kg}^{-1}$ fazla, $>5.0 \mathrm{mg} \mathrm{kg}^{-1}$ çok fazla olarak kabul edilmiştir (Miller 1998; Eyüpoğlu ve ark. 2000). Toprak örneklerinin alındığı yerlere göre bir değerlendirme yapılacak olursa, Korkuteli ve Döşemealtı yöresi topraklarının hepsi, Aksu yöresi topraklarının \%70'inin bor içeriklerinin yeter seviyenin altında olduğu görülmüştür. Örnekleme alanlarının tamamına ait bir değerlendirme yapılacak olduğunda, örneklerin \%90'sinin bor içeriklerinin yeter seviyenin altında olduğu belirlenmiştir (Çizelge 3). Sillanpaa (1990) tarafından Türkiye'de yapılan bir çalışmada toplam 298 örneğin ortalama B konsantrasyonunun $1.10 \mathrm{mg} \mathrm{kg}{ }^{-1}$ olduğu tespit edilmiştir. Gezgin ve ark. (2002)'nin Konya topraklarının B kapsamlarının belirlenmesi için yaptıkları bir çalışmada, ortalama olarak 2.48 $\mathrm{mg} \mathrm{kg}^{-1} \mathrm{~B}$ içerdiklerini belirlemişlerdir.

Yaprak örneklerinin bor konsantrasyonları incelendiğinde dağılım 0.04-17.51 mg kg-1 aralığında değişmiş ve ortalama bor konsantrasyonu $5.33 \mathrm{mg} \mathrm{kg}^{-1}$ olarak belirlenmiştir (Çizelge 4). Reuter ve Robinson (1997)'de bayrak yaprak bor yeterlilik konsantrasyonu 3-25 mg kg-1 olarak belirtilmiştir. Yörelere göre yaprak örneklerinin bor beslenme durumları değerlendirildiğinde, fazla düzeyde bor içeren örneğe rastlanmamıştır. Korkuteli örneklerinin \%40'1, Döşemealtı \%20'si ve Aksu örneklerinin \%10'unun yetersiz düzeyde bor içerdiği tespit edilmiştir (Çizelge 5). Tüm örnekler değerlendirildiğinde yaprakların \%77'sinin bor içeriklerinin yeterli düzeyde olduğu görülmüş̧ür.

Dane örneklerinin bor konsantrasyonları 0.01-6.82 mg kg-1 aralığında değişmiş ve ortalama bor konsantrasyonu 2.036 $\mathrm{mg} \mathrm{kg}^{-1}$ olarak hesaplanmıştır (Çizelge 6). Reuter ve Robinson (1997)'de dane bor yeterlilik konsantrasyonu $2 \mathrm{mg} \mathrm{kg}^{-1}$, toksik konsantrasyonu ise $9-37 \mathrm{mg} \mathrm{kg}^{-1}$ olarak belirtilmiştir. Çalışmamızdaki dane örneklerinin bor konsantrasyonlarının değerlendirilmesinde, Reuter ve Robinson (1997) tarafindan verilen değerler adapte edilerek, $2 \mathrm{mg} \mathrm{kg}^{-1}$ 'den düşük ise yetersiz; 2-8 $\mathrm{mgkg}^{-1}$ arasında ise yeterli; $8 \mathrm{mg} \mathrm{kg}^{-1}$, dan büyük ise fazla olarak kabul edilmiştir. Buna göre yörelerin dane örneklerinin bor beslenme durumları değerlendirildiğinde, fazla düzeyde bor içeren örneğe rastlanmamıştır. Aksu ve Döşemealtı yöresi örneklerinin \%80'i, Korkuteli yöresi örneklerinin \%20'sinin yetersiz düzeyde bor içeriği tespit edilmiştir (Çizelge 7). Tüm örnekler değerlendirildiğinde danelerin \%60'ının bor içeriklerinin yetersiz düzeyde olduğu görülmüştür. Daha önce yapılan çalışmalar buğdayda bor uygulamasının danenin bor içeriğini arttırabileceğini ortaya koymuştur (Güneş ve ark. 2003; Furlani ve ark. 2003).

Çizelge 2. Toprak örneklerinin bor konsantrasyonları $\left(\mathrm{mg} \mathrm{kg}^{-1}\right)$.

Table 2. Boron concentrations of soil samples $\left(\mathrm{mg} \mathrm{kg}^{-1}\right)$.

\begin{tabular}{cccc}
\hline Örnek No & Aksu & Döşemealtı & Korkuteli \\
\hline 1 & 1.115 & 0.016 & 0.226 \\
2 & 0.513 & 0.019 & 0.154 \\
3 & 0.515 & 0.305 & 0.137 \\
4 & 0.092 & 0.142 & 0.094 \\
5 & 0.092 & 0.116 & 0.025 \\
6 & 0.022 & 0.188 & 0.185 \\
7 & 0.021 & 0.094 & 0.335 \\
8 & 0.010 & 0.065 & 0.233 \\
9 & 0.219 & 0.076 & 0.087 \\
10 & 0.246 & 0.133 & 0.174 \\
Minumun & 0.010 & 0.016 & 0.025 \\
Maksimum & 1.115 & 0.305 & 0.335 \\
Ortalama & 0.285 & 0.015 & 0.165 \\
\hline
\end{tabular}


Çizelge 3. Toprakların bor konsantrasyonlarının değerlendirilmesi.

Table 3. Evaluation of boron concentrations of soils.

\begin{tabular}{ccccc}
\hline & \multicolumn{4}{c}{ Değerlendirme (mg kg-1) } \\
\cline { 2 - 5 } Örnekleme & Yetersiz & Yeterli & Fazla & Çok \\
Bölgesi & $\mathbf{0 . 5}$ & $\mathbf{0 . 5 - 2}$ & $\mathbf{2 . 1 - 5}$ & Fazla 5> \\
\hline Aksu & $\% 70$ & $\% 30$ & - & - \\
Döşemealtı & $\% 100$ & - & - & - \\
Korkuteli & $\% 100$ & - & - & - \\
Genel & $\% 90$ & $\% 10$ & - & - \\
\hline
\end{tabular}

Çizelge 4. Yaprak örneklerinin bor konsantrasyonları $\left(\mathrm{mg} \mathrm{kg}^{-1}\right)$.

Table 4. Boron concentrations of the leaf samples $\left(\mathrm{mg} \mathrm{kg}^{-1}\right)$.

\begin{tabular}{cccc}
\hline Örnek No & Aksu & Döşemealtı & Korkuteli \\
\hline 1 & 6.673 & 2.078 & 5.267 \\
2 & 7.298 & 2.375 & 2.740 \\
3 & 1.881 & 3.158 & 4.352 \\
4 & 7.457 & 4.533 & 1.181 \\
5 & 5.951 & 4.749 & 9.045 \\
6 & 4.602 & 7.990 & 3.130 \\
7 & 7.783 & 5.269 & 0.039 \\
8 & 17.51 & 3.012 & 2.803 \\
9 & 6.115 & 3.340 & 6.546 \\
10 & 12.90 & 4.829 & 5.381 \\
Minumun & 1.881 & 2.078 & 0.039 \\
Maksimum & 17.51 & 7.990 & 9.045 \\
Ortalama & 7.817 & 4.133 & 4.048 \\
\hline
\end{tabular}

Çizelge 5. Yaprak örneklerinin bor konsantrasyonlarının değerlendirilmesi.

Table 5. Evaluation of the leaves samples boron concentrations.

\begin{tabular}{cccc}
\hline & \multicolumn{3}{c}{ Değerlendirme (mg kg-1) } \\
\cline { 2 - 4 } Örnekleme Bölgesi & Yetersiz $<3$ & Yeterli 3 - 25 & Fazla 25 < \\
\hline Aksu & $\% 10$ & $\% 90$ & - \\
Döşemealtı & $\% 20$ & $\% 80$ & - \\
Korkuteli & $\% 40$ & $\% 60$ & - \\
Genel & $\% 23$ & $\% 77$ & - \\
\hline
\end{tabular}

Çizelge 6. Dane örneklerinin bor konsantrasyonları $\left(\mathrm{mg} \mathrm{kg}^{-1}\right)$.

Table 6. Boron concentrations of grain samples $\left(\mathrm{mg} \mathrm{kg}^{-1}\right)$.

\begin{tabular}{cccc}
\hline Örnek No & Aksu & Döşemealtı & Korkuteli \\
\hline 1 & 0.726 & 0.010 & 2.674 \\
2 & 1.513 & 0.065 & 0.010 \\
3 & 0.946 & 1.134 & 5.794 \\
4 & 0.807 & 0.359 & 4.065 \\
5 & 6.356 & 2.331 & 2.756 \\
6 & 0.010 & 1.764 & 3.002 \\
7 & 0.011 & 0.699 & 1.028 \\
8 & 2.505 & 0.101 & 4.189 \\
9 & 0.282 & 6.820 & 4.880 \\
10 & 1.003 & 0.242 & 5.005 \\
Minumun & 0.010 & 0.010 & 0.010 \\
Maksimum & 6.356 & 6.820 & 5.794 \\
Ortalama & 1.416 & 1.353 & 3.339 \\
\hline
\end{tabular}

Çizelge 7. Dane örneklerinin bor konsatrasyonlarının değerlendirilmesi Table 7. Evaluation of boron concentrations of grain samples

\begin{tabular}{cccc}
\hline & \multicolumn{3}{c}{ Değerlendirme (mg kg-1) } \\
\cline { 2 - 4 } Örnekleme Bölgesi & Yetersiz < & Yeterli 2 - 8 & Fazla 8 < \\
\hline Aksu & $\% 80$ & $\% 20$ & - \\
Döşemealtı & $\% 80$ & $\% 20$ & - \\
Korkuteli & $\% 20$ & $\% 80$ & - \\
Genel & $\% 60$ & $\% 40$ & - \\
\hline
\end{tabular}

\section{Sonuc}

Toprak örneklerinin nerdeyse tamamında (\%90) bor noksan tespit edilirken, yaprak örneklerin büyük kısmında (\%77) bor yeterli bulunmuştur. $\mathrm{Bu}$ durumun muhtemel sebebi olarak yapraktan yapılan bor gübrelemesinin olduğu düşünülmektedir. Çıkılı ve Yalçın (2012) bor noksan alanlarda ve kuru koşullarda buğday yetiştiriciliğinde, yapraktan bor uygulamasının bitkinin ihtiyacını karşılamada kullanılabileceğini bildirmişlerdir. Elde edilen bir diğer sonuçta dane örneklerinin \%60'inda bor düzeyinin yetersiz çıkmasıdır. Yaprak bor sonuçlarını referans olarak göz önünde bulundurursak, yapraktan daneye yeterli bor taşınımının olmadığı görülmektedir. Araştırıcılar arasında fikir birliği olmamasına karşın, borun bitki bünyesindeki taşınımının ksilem yoluyla ve transpirasyona bağlı olarak gerçekleştiği konusundaki görüşler ağırlık kazanmaktadır (Pate 1975; Shelp ve ark. 1992). Bu durumun bitki dokularına bor taşınımını sınırlayabileceği böylece bitki kısımları arasında bor konsantrasyonlarında farklılığa sebep olabileceği düşünülmektedir. Bahsedilen durumun bor uygulama dozu, zamanı ve tekrar sayısı gibi değişkenlerin optimize edilmesi ile ortadan kaldırılabileceği ve bu konudaki çalışmaların sürdürülmesi gerektiği kanaatine varılmıştır.

\section{Kaynaklar}

Bartleta RJ, Picarelli CJ (1973) Availability of boron and phosphorus as affected by liming on acid potato soil. Soil Sci. 116: 77-83.

Bennett OL, Mathias EL (1973) Growth and chemical composition of crownvetch as affected by lime, boron, soil source and temperature regime. Agronomy Journal 65: 587-593.

Bergmann W (1992) Nutritional disorders of plants. Developments Visual and Analytical Diagnosis Jena, s. 165-185.

Black CA (1957) Soil Plant. John Wiley and Sons Inc., New York.

Black CA (1965) Methods of Soil Analysis Part 2, Amer. Society of Agronomy Inc., Publisher Madisson, Wilconsis, U.S.A., s. 13721376.

Bouyoucos GJ (1952) Recalibration of the hydrometer for making mechanical analysis of soils. Agronmy Journal 43: 434-438.

Brown PH, Bellaloui N, Wimmer MA, Bassil ES, Ruiz J, Hu H, Pfeffer H, Dannel F, Römheld V (2002) Boron in plant biology. Plant Biology 4: 205-223.

Cartwright B, Tiller KG, Zarcinas BA, Spouncer LR (1983) The chemical assessment of the boron status of soils. Aust. J. Soil Res. 21: 321-232.

Cheng CH, Rerkasem B (1993) Effect of boron on pollen viability in wheat. Plant and Soil 155/156: 313-315. 
Çıkılı Y, Yalçın SR (2012) Yapraktan uygulanan borun buğdayın verimi, bazı verim unsurları ve tanede $\mathrm{B}, \mathrm{Zn}$ ve $\mathrm{Ca}$ kapsamina etkisi. HR. Ü. Z. F. Dergisi 16(1): 17-24.

Eaton FM (1944) Deficency, Toxicity and accumulation of borron in plants. J. Agric. Res. 69: 237-277.

Evliya H (1964) Kültür Bitkilerinin Beslenmesi. Ankara Üniv. Ziraat Fak. Yayınları Sayı: 10.

Eyuboglu F, Kurucu N, Gucdemir I, Talas S (2002) Boron status of Central Anatolian soils. Int. Conference on Sustainable Land Use and Management. Canakkale, Turkey.

Eyüpoğlu F, Güçdemir İH, Kurucu N, Talas S (2000) Orta Anadolu topraklarının bitkiye yarayışlı bor bakımından genel durumu. Toprak ve Gübre Araştırma Enstitüsü Yayını, Ankara s. 1-47.

Furlani AMC, Carvalho CP, Freitas JG de, Verdial MF (2003) Wheat cultivar tolerance to boron deficiency and toxicity in nutrient solution. Scientia Agricola 60(2): 359-370.

Gezgin S, Dursun N, Hamurcu M, Harmankaya M, Önder M, Sade B, Topal A, Soylu S, Akgün N, Yorgancılar M, Ceyhan E, Çiftçi N, Acar B, Gültekin İ, Işık Y, Şeker C, Babaoğlu M (2002) Determination of B contents of soils in Central Anatolian cultivated lands and its relations between soil and water characteristics. In: Goldbach HE, Rerkasem B, Wimmer MA, Brown PH, Thellier, M, Bell RW, editors. Boron in Plant and Animal Nutrition. New York, NY, USA: Kluwer Academic Publishers, pp. 391-400.

Goldberg S (1997) Reaction of boron with soils. "Alınmıştır: Plant and Soil. Proceedings. (ed) Bell, R.W. and Rerkasem, B. Kluwer Academic Publishers, Dordrecth, the Netherlands". pp. 193: 35-48.

Gupta UC (1993) Introduction. In: Boron and Its Role in Crop Production. Ed. U.C Gupta. P 1. CRC Press. Boca Raton, FL, USA.

Gupta UC, Jame YW, Campbell CA, Leyshon AJ, Micholaichuk W (1985) Boron toxicity and deficiency, a review. Can. J. of Soil Sci. 65: 381-409.

Güneş A, Alpaslan M, İnal A, Adak MS, Eraslan F, Çiçek N (2003) Effects of boron fertilization on the yield and some yield components of bread and durum wheat. Turk J. Agric. For. 27: 329335.

Jackson ML (1967) Soil Chemical Analysis. Prentice Hall of India Private Limited, New Delhi.

Kacar B (1972) Bitki ve Toprağın Kimyasal Analizleri: 2. Bitki Analizler, Ankara Üniv. Ziraat Fakültesi Yayınları: 453, Uygulama Klavuzu: 155.

Kacar B, İnal A (2008) Bitki Analizleri. Nobel Yayınları, Yayın No: 1241, Fen Bilimleri, 892. Nobel Yayın Dağıtım Ltd. Şti. Ankara, s. 892.

Kellog W (1952) Our Garden Soil. The Macmillan Company, New York.

Keren R, Bingham FT (1985) Boron in water, soils and plants. Adv. Soil Sci. 1: 230-276.

Kızılgöz İ, Özberk İ (2005) Sulanan koşullarda makarnalık ve ekmeklik buğdayın borla beslenme durumunun belirlenmesi. Süleyman Demirel Üniversitesi, Fen Bilimleri Enstitüsü Dergisi 9-3.
Laila EAN, Adel EAA (2002) Effect of boron deficiency on some physiological and biochemical aspects during the developmental stages of wheat (Triticum aestivum L.) plant. Online Journal of Biological Sciences 2(7): 470-476.

Marschner H (1995) Mineral Nutrition of Higher Plants. Academic Press, Second Edition, pp. 379-396.

Marschner H (1976) Mineral metabolism, short and long distance transport. Fortschr. Botany 38: 71-80.

Michael G, Wilberg E, Kouhsiahai-Tork K (1969) Boron deficiency Induced by high air humidity. Z. Pflanz. Bodenkunde 122: 1-3.

Miller SS (1998) Begin Orchard Nutrition Program: Determining Nutritional Status for Apple and Peach. USD-ARS, Appalachian Fruit Research Station Kearneysville, West Virgin 25430 USA.

Nelson DW, Sommers LE (1982) Total carbon, organic carbon, organic matter. In: AL Madison (Ed.), Methods of Soil Analysis Part 2. Chemical and Microbiological Properties Second Edition. Wisconsin, USA, American Society of Agronomy Inc., pp. 539579.

Pant J, Rerkasem B, Noppakoonwong R (1998) Effect of water stress on the boron response of wheat genotypes under low boron field conditions. Plant and Soil 202: 193-200.

Pate JS (1975) Exchanges of solutes between phloem and xsylem and circulation in the whole plant. "Alınmıştır: Encyclopedia of Plant Physiology, New series. Vol.1, Transport of plants. I. Phloem transport. (ed) Zimmermann, M.H. and Miburn, J.A., SpringerVerlag, New York". pp. 451-473.

Rerkasem B, Jamjod S (1989) Correcting boron deficiency induced ear sterility in wheat and barley. Thai J. Soils Fert. 11: 200-209.

Reuter DJ, Robinson JB (1997) Plant Analysis, an Interpretation Manual, 2nd Edition, CSIRO Publishing, Collingwood, pp. 252.

Shelp BJ, Shattuck VI, McLellan D, Liu L (1992) Boron nutrition and composition of glucosinolates and soluble nitrogen compounds in two broccoli (Brassica oleracea var. Italica) cultivars. Can. Plant Sci. 72: 889-899.

Shorrocks VM (1997) The occurrence and correction of boron deficiency. Plant and Soil 193: 121-148.

Sillanpaa M (1990) Micronutrient Assessment at the Country Level: An International Study. FAO Soils Bulletin No. 63, FAO, Rome, Italy.

Subedi KD, Budhathoki CB, Subedi M (1997) Variation in sterility among wheat (Triticum aestivum L.) genotypes in response to boron deficiency in Nepal. Euphytica 95: 21-26.

Taban S, Erdal İ (2000) Bor uygulamasının değisik buğday çeşitlerinde gelişme ve toprak üstü aksamda bor dağılımı üzerine etkisi, Turkish Journal of Agriculture and Forestry 24: 255-262.

TÜİK (2018) Türkiye İstatistik Kurumu. http://www.tuik.gov.tr/PreTablo.do?alt id=1001. Erişim 21 Nisan 2019.

US Soil Survey Staff (1951) Soil Survey Manual. U.S. Department Agriculture Handbook. No.18. U.S Government Printing Office Washington. 